\title{
Oleuropein Reduces Prdx1 Expression, Cell Proliferation and Viability in K562 Human Leukemia Cells
}

\author{
Sophia R. Fagan ${ }^{1}$, Natalie M. Fulco ${ }^{2}$, Dr. Shelley A. Phelan PhD ${ }^{3 *}$ \\ ${ }^{1}$ Research Associate, Pediatric Genomics Discovery Program, Yale Medicine, U.S.A \\ ${ }^{2}$ Fairfield University, Fairfield CT, U.S.A \\ ${ }^{3}$ Professor, Department of Biology, Fairfield University, Fairfield CT, U.S.A
}

*Corresponding Author: Dr. Shelley A. Phelan, Professor, Department of Biology, Fairfield University, Fairfield CT, U.S.A., Email: sphelan@fairfield.edu

\begin{abstract}
Oleuropein is one of the two main phenolic compounds derived from olive leaves. Numerous studies have found that the polyphenols contained in olive leaves possess strong antioxidant properties, and increase apoptosis in many types of cancer cells, suggesting its possible efficacy as an anti-cancer treatment. The purpose of this study was to examine the effects of oleuropein extract on cell growth and viability of the K562 human leukemia cell line. It was first demonstrated that cells treated with 200 or $400 \mu \mathrm{g} / \mathrm{mL}$ oleuropein exhibited a significant reduction in cell number and viability after four days, as compared to ethanol-treated controls. Cells treated with $200 \mu \mathrm{g} / \mathrm{mL}$ oleuropein showed approximately $90 \%$ reduction in cell density and viability after four days of treatment, while the $400 \mu \mathrm{g} / \mathrm{mL}$ concentration resulted in $100 \%$ toxicity by the fourth day. It was also found that a two-fold elevation in LDH release within 24 hours of treatment with 200 $\mu \mathrm{g} / \mathrm{mL}$ oleuropein, confirming cytotoxicity. Examination of caspase-1 activity revealed an increase in apoptosis within 24 hours. To begin to explore a mechanism of action, we examined the effect of oleuropein on expression of the Peroxiredoxin (Prdx) family of antioxidant proteins. A concentration of $200 \mu \mathrm{g} / \mathrm{mL}$ oleuropein reduced Prdxl expression by about 50\% after eight and twenty-four hours. This study reveals new data on the specific effects of oleuropein on K562 cells, and the regulation of Prdxl as a possible mechanism of action. Together with previous reports, this research provides further insight into our understanding of natural products as anti-cancer agents.
\end{abstract}

Keywords: Oleuropein, K562 human leukemia, natural anti-cancer agents, olive leaves, Peroxiredoxin expression

\section{INTRODUCTION}

Olive leaves have been used in Mediterranean cultures for centuries because they are believed to possess notable health benefits. Olive leaves are largely harvested in Asia, Arabian Peninsula, Indian subcontinent, and Mediterranean regions of the world (20). Studies have shown that olive leaves have many known useful pharmacological effects, and they have ultimately been used to treat a wide variety of ailments (16). There are many reports that Mediterranean people have created olive leaf tea, powder, or extract as a natural remedy to various diseases. Historically, the most traditional uses of olive leaves have been; oral ingestion for stomach and intestinal diseases, chewed as a mouth cleanser, dried and orally ingested for diarrhea and urinary tract infections, added to hot water to treat high blood pressure as well as encourage urination, and the addition of an extraction of the dried plant to hot water in order to treat bronchial asthma (20).

Olive leaf extract contains higher levels of polyphenols than extra virgin olive oil. Polyphenols are an aromatic structure with varying number of hydroxyl groups (3). These aromatic structures then attach together in various orientations to create distinct polyphenols (3). The total polyphenol content found in olive tree leaves is $2.058 \mathrm{mg}$ per $100 \mathrm{~g}$ (20). Olive trees are predominantly grown in the Mediterranean region where they face periods of extended sunlight and pathogenic insect attack. As a response to these conditions, olive trees create a high volume of polyphenols which are stored in the leaves of the trees.

Polyphenols have been shown to lower glucose levels in the blood stream, lower cholesterol levels, and have cardio protective properties (16). The polyphenols from olive leaves have proven to be anti-inflammatory and act as 
antioxidants through protecting DNA by scavenging free radicals and removing potentially harmful oxidizing agents (3). These phenolic compounds from olive leaves are of growing interest in the cancer-research field due to the anti-proliferative and apoptosis inducing properties that they have on various cancer cell lines (16). Olive leaves have been demonstrated to have the highest antioxidant content compared to the rest of the tree (20).

Oleuropein is a naturally occurring extract that comes from olive leaves and is part of the oleuropeosides phenolic compound group of olive leaf phenolic components. Oleuropein is the most abundant phenol and accounts for 6$9 \%$ of dry matter in the olive leaf (21). It is present in the highest amounts in the unprocessed olive fruit and leaves. In aqueous extracts from the olive leaves it is the major compound, accounting for approximately $73 \%$ of the total compounds identified. Oleuropein itself is an antioxidant, which inhibits oxidation that can cause free radical accumulation leading to damaged proteins, DNA, and cell membranes in the cells. Additionally, oleuropein inhibits the oxidation of low density lipoproteins in cells (21). When there is an increase of antioxidants there will be an overall reduction in chronic diseases (20). It is believed that the ability of oleuropein to prevent the formation of free radicals is due to its ability to form several bonds with metal ions such as $\mathrm{Cu}$ and $\mathrm{Fe}$. This in turn catalyzes the free radical generation reactions and inhibits various inflammatory enzymes such as lipoxygenases. This is successfully done without affecting the cyclooxygenase pathway which forms prostanoids. Oleuropein has also been shown to be a scavenger superoxide anion and possesses the ability to inhibit the respiratory burst of neutrophils and hypochlorous acid-derived radicals. It also is known to scavenge hydroxyl radicals as well as 1,1-diphenyl-2picrylhydrazyl radicals (20).

Previous studies have examined the effect of oleuropein treatments on cell proliferation and apoptotic induction of various cancer cell lines. Oleuropein has been found to be cytotoxic to human osteosarcoma cancer cells by inhibiting their ability to proliferate under the extracts conditions (13). Further studies have found that oleuropein reduced cell viability and induced thiol group modifications in two different prostate cancer cell lines; LNCaP and DU145 (1). Yet another showed that oleuropein inhibited cell proliferation and induced apoptosis in MCF-7 breast cancer cells through the mitochondrial pathway (6). Yet another study tested the cytotoxic action of oleuropein by itself or in conjunction with chemotherapeutics on A375 human melanoma cells. It was found that oleuropein was able to stimulate an apoptotic response in the cell at a dose of $500 \mu \mathrm{M}$. This dose of oleuropein affected cell proliferation and induced the down regulation of the pAKT/pS6 pathway (19). Together, there is mounting evidence that the oleuropein extract can successfully be used in a wide variety of cancer cell lines to affect cell proliferation and induce cell death.

Peroxiredoxins (Prdxs) are a large family of proteins that is highly conserved in all cells. The main role of Prdxs is to regulate cellular and lipid peroxide levels that accumulate in the cell by way of rapidly detoxifying hydrogen peroxide, organic hydroperoxides, and peroxynitrite (14). Members of the peroxiredoxin family share a thioredoxin fold and contain a highly-reactive active site peroxidatic cysteine, which functions to reduce peroxide substrates $(5,18)$. Peroxiredoxinmediated regulation of $\mathrm{H}_{2} \mathrm{O}_{2}$ levels facilitates their role in cell proliferation, differentiation, and apoptotic pathways $(11,14)$. Much research has demonstrated that peroxiredoxins can function as tumor suppressors, and peroxiredoxin levels have been shown to be up regulated in various cancers $(4,8-10,15,17)$. The present study sought to investigate the effect of oleuropein on growth and viability in the K562 human leukemia cell line, and also investigate whether oleuropein would regulate the Peroxiredoxin family of antioxidant proteins.

\section{MATERIALS AND MeTHOdS}

\subsection{Preparation of Oleuropein}

Oleuropein was ordered from Sigma-Aldrich at $>98 \%$ purity, Catalog \#: 12247. The oleuropein extract was dissolved in $70 \%$ ethanol to create a $100 \mathrm{mg} / \mathrm{mL}$ stock solution. This stock solution was stored at $-20^{\circ} \mathrm{C}$ and protected from light.

\subsection{K562 Cells}

The human leukemia K562 cell line was purchased from ATCC. The cells were culture in media comprised of 90\% Iscove's Modified Dulbecco's Medium (IMDM) catalog \#SH30228.01 purchased from GE Life Sciences and $10 \%$ Fetal bovine serum (FBS) ATCC 302020. Cells were grown and maintained at $37^{\circ} \mathrm{C}$ in a humidified $5 \% \mathrm{CO}_{2}$ incubator. 


\subsection{Analysis of Cell Growth and Viability}

In order to analyze the effect of oleuropein treatment on cell growth and viability cells were plated at a density of $0.5 \times 10^{5}$ cells $/ \mathrm{mL}$ in a $96-$ well plate. In replicates of six, cells were treated with $0.14 \%$ ethanol, $0.28 \%$ ethanol, $100 \mu \mathrm{g} / \mathrm{mL}$ oleuropein, $200 \mu \mathrm{g} / \mathrm{mL}$ oleuropein, or $400 \mu \mathrm{g} / \mathrm{mL}$ oleuropein. (Ethanol controls included equivalent amounts of $70 \%$ ethanol to the corresponding oleuropein treatments as vehicle controls.) Each day over a four-day period, cells in each well were counted using a hemocytometer and a Trypan Blue Exclusion Assay to determine viable cells. Statistical analysis of data were carried out using a twotailed student's t-test.

\subsection{Measurement of Cytotoxicity}

To examine the effect of the cytotoxicity of the oleuropein compound on the K562 cells a Lactate Dehydrogenase (LDH) Assay was used. This assay is a colorimetric method for quantifying cellular cytotoxicity by measuring the release of LDH into cell culture media when the plasma membrane is damaged. K562 cells were plated at a density of $0.5 \times 10^{5}$ cells $/ \mathrm{mL}$. Replicates of six were performed for each of untreated, $0.14 \%$ ethanol, and $200 \mu \mathrm{g} / \mathrm{mL}$. Oleuropein and media levels of LDH levels were measured daily over a 72 hour period by measuring formazan absorbancy at $490 \mathrm{~nm}$. Statistical analysis of data were carried out using a two-tailed student's t-test.

\subsection{Measurement of Apoptosis}

To examine the effect of oleuropein treatment on cell apoptosis of the K562 cell line, a Caspase 1-ICE Assay was used. K562 cells were plated at a density of $0.5 \times 10^{5}$ cells $/ \mathrm{mL}$. Replicates of four were performed for untreated and $200 \mu \mathrm{g} / \mathrm{mL}$ oleuropein treated cells. The activation of caspase-1 was assessed my measuring the enzymatic product absorbance at $400 \mathrm{~nm}$ after 24 and 48 hours. Statistical analysis of data were carried out using a twotailed student's t-test.

\subsection{Measurement of Peroxiredoxin Expression}

Cells were plated at a density of $5.0 \times 10^{5}$ cells $/ \mathrm{mL}$ in a 24-well plate. In replicates of three, cells were untreated or treated with 200 $\mu \mathrm{g} / \mathrm{mL}$ oleuropein for 8 or 24 hours. Protein was extracted using the Mammalian Protein Extraction Reagent (MPER). Proteins were quantified using Coomassie Plus, and equivalent amounts of total protein were separated by SDS-PAGE gel electrophoresis followed by transfer to a PVDF membrane. Western blotting was used to analyze protein expression of Peroxiredoxins using primary antibodies from Abcam: Prdx 1 (AB58252), Prdx2 (AB109367), $\quad \operatorname{Prdx} 3$ (AB16761), Prdx4 (AB59542), and Prdx6 (AB16947). An antibody to Gapdh (SigmaG9545) was used as a control. Alkalinephosphatase conjugated secondaries were used, followed by the CDP-Star reagent. Chemiluminescence was detected and images captured using the GBOX system. SynGene Gene tools software was used for band quantification.

\section{ReSUlts}

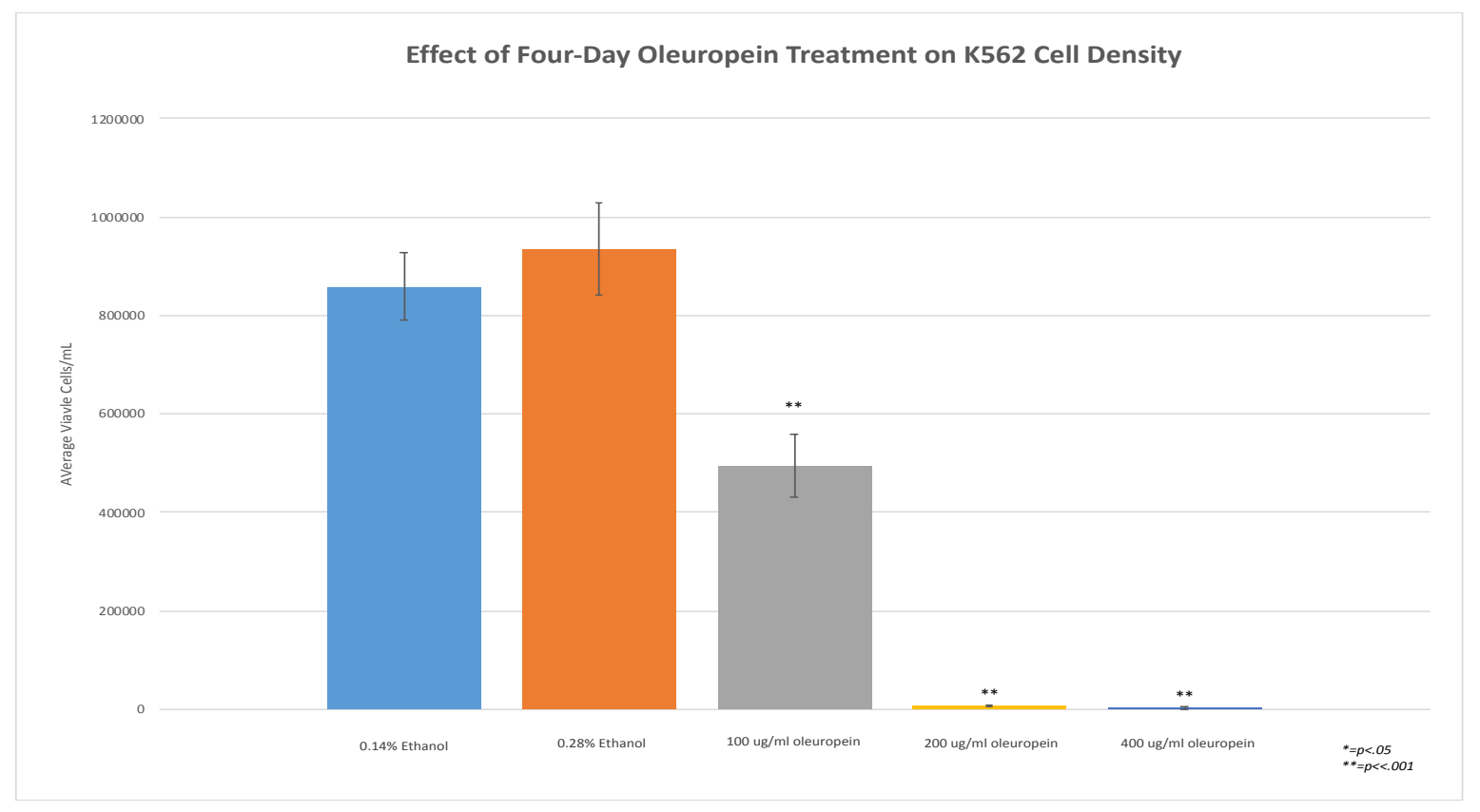

Figure 1A 


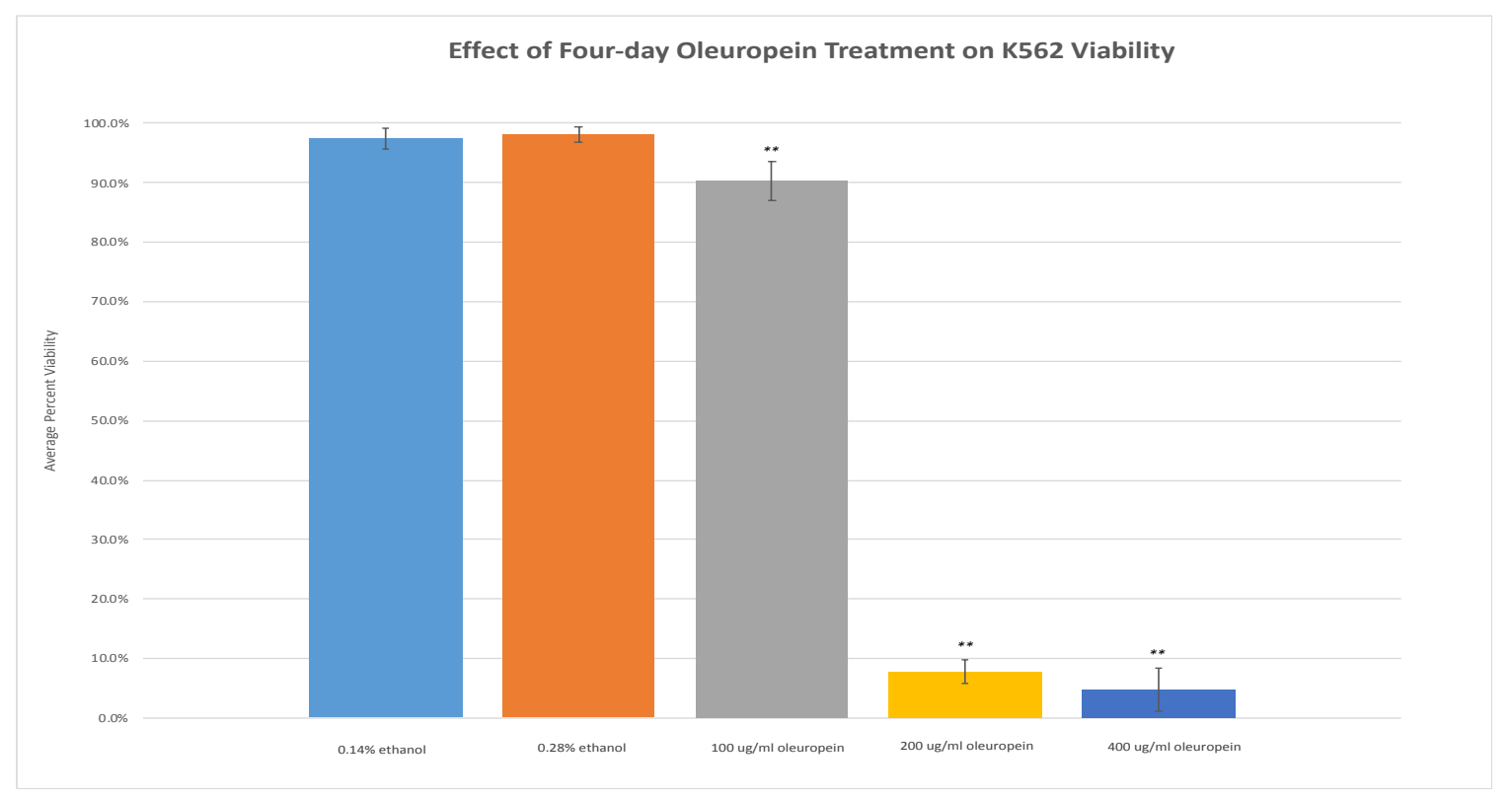

Figure 1B

Figure 1. Effect of Oleuropein on K562 Cell Density and Viability. K562 cells were treated with varying concentrations of oleuropein (or ethanol controls) for four days, and viable cell density and \% viability were measured using trypan blue exclusion. (A) Average viable cell density; (B) Percent viability. Averages are shown (+/-stdev). A student's t-test was used for statistical analysis.

As shown in Figure 1, after four days of oleuropein treatment, there was a marked decrease in cell density for cells treated with $200 \mu \mathrm{g} / \mathrm{mL}$ and $400 \mu \mathrm{g} / \mathrm{mL}$ oleuropein, as compared to ethanol control-treated cells (Fig1A).

In contrast, a much more modest, yet significant, reduction was observed with a concentration of $100 \mu \mathrm{g} / \mathrm{mL}$. Upon investigation of cell viability in these cultures, we found a significant reduction in cell viability with all three concentrations of oleuropein (Fig 1B).

The reduction in viability for the $100 \mu \mathrm{g} / \mathrm{ml}$ concentration was very slight, dropping to only $90 \%$ after four days, while the higher concentrations resulted in a marked decrease in viability to around $10 \%$.

The time course of the observed effect was then investigated by measuring cell density and viability daily over a four-day period. While controls were noticeably growing after two days, there was almost complete growth inhibition as early as two days with both concentrations of oleuropein treatment (Fig 2A).

Cell number did not increase in either treatment for the remaining two days of the experiment. Likewise, a significant reduction in viability was observed as early as one day after treatment in both concentrations of oleuropein (Fig 2B).

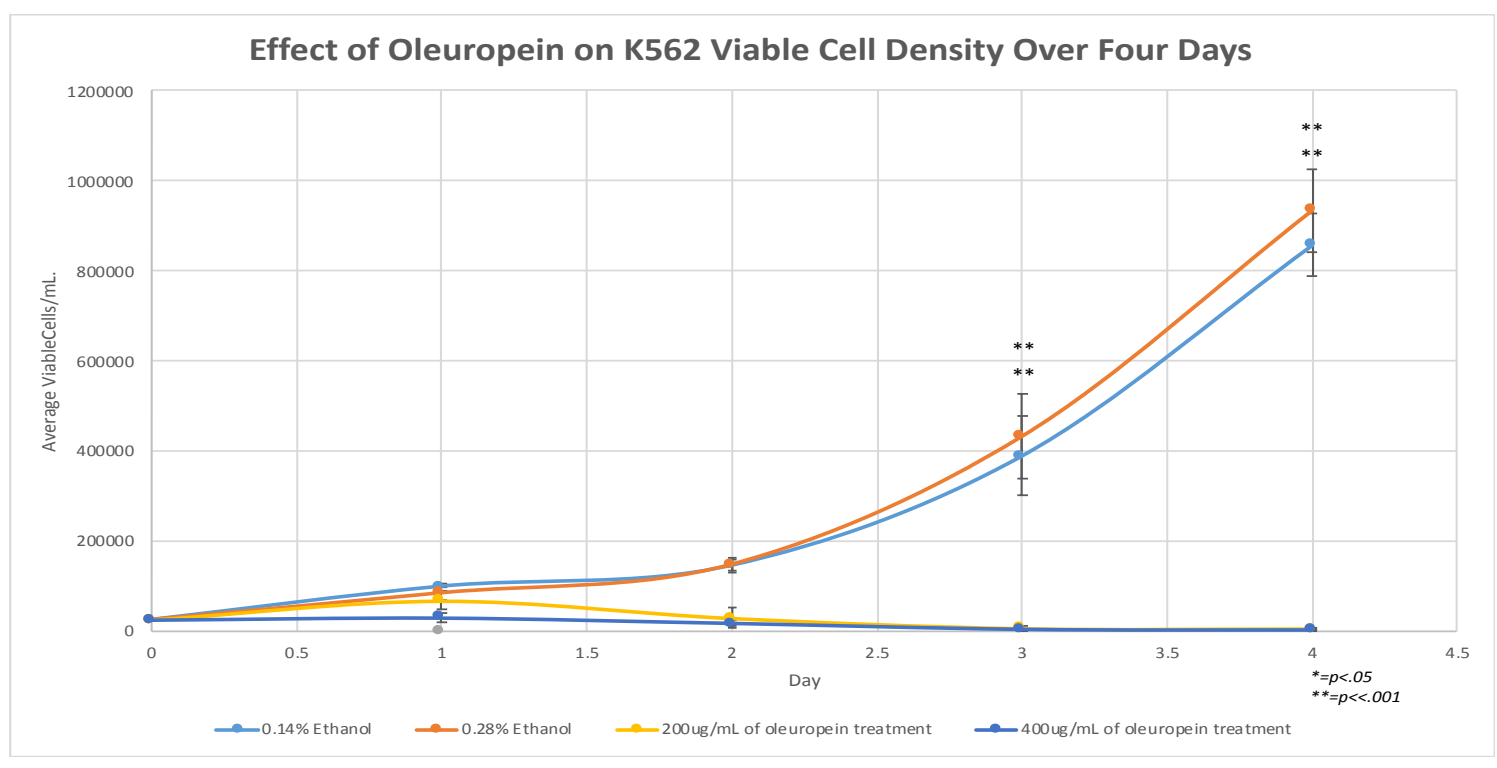

Figure 2A 


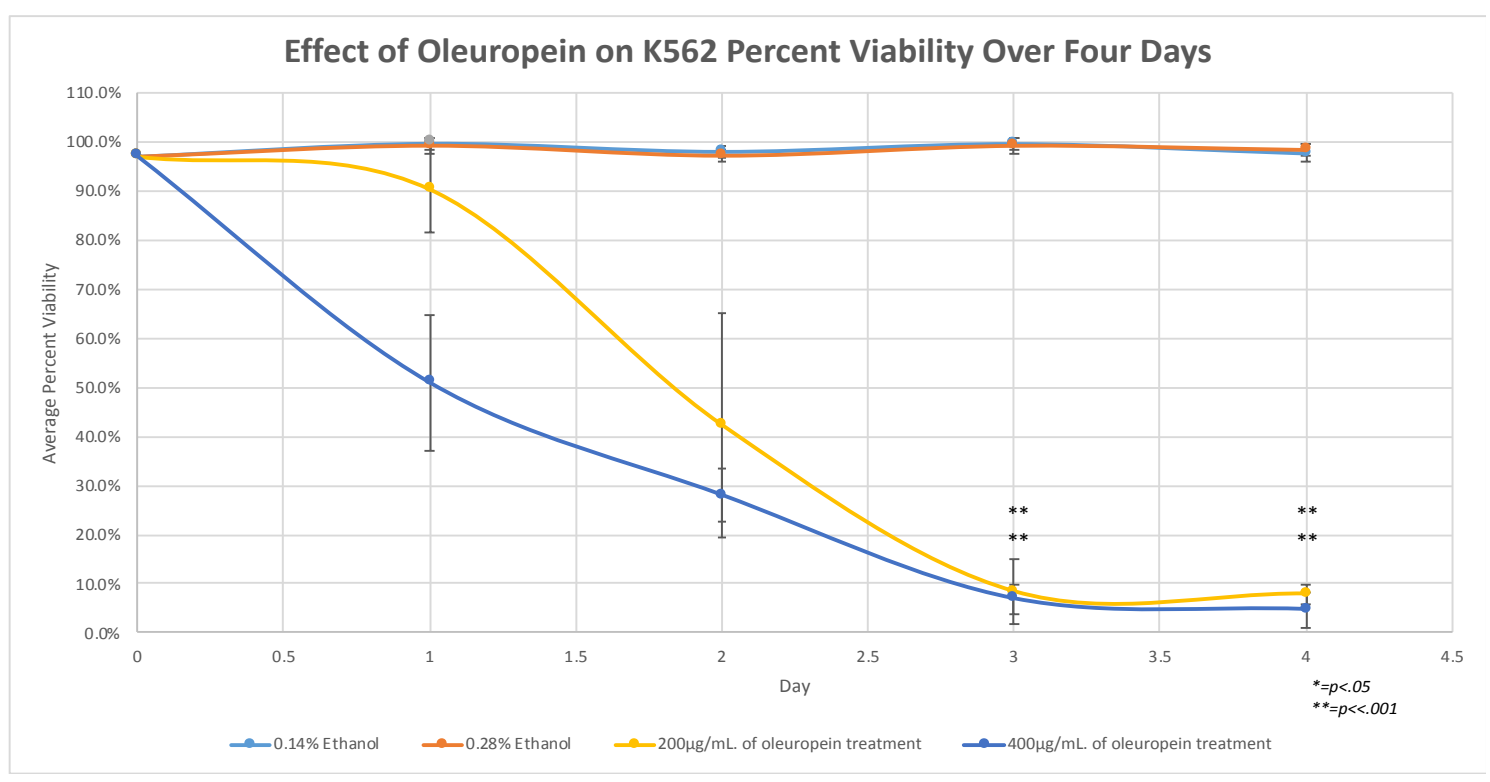

Figure 2B

Figure 2. Kinetics of the Effect of Oleuropein on K562 Cell Density and Viability. K562 cells were treated with $200 \mu \mathrm{g} / \mathrm{mL}$ and $400 \mu \mathrm{g} / \mathrm{mL}$ concentrations of oleuropein (or ethanol controls) for four days, and viable cell density and \% viability were measured daily using trypan blue exclusion. (A) Average viable cell density; (B) Percent viability. Averages are shown (+/-stdev). A student's t-test was used for statistical analysis.

The magnitude of the reduction differed, with the lower concentration exhibiting nearly $90 \%$ viability after one day, while the higher concentration dropped to about $50 \%$ viability after one day. Viability dropped to under $50 \%$ by day two in both concentrations, and further dropped to approximately $10 \%$ viability by days three and four.

To investigate whether oleuropein was inducing cytotoxicity in these cells, the release of lactate dehydrogenase was measured in a standard $\mathrm{LDH}$ release assay. It was decided to use the lower concentration of oleuropein $(200 \mu \mathrm{g} / \mathrm{ml})$ for the remaining experiments. As shown in Figure 3, LDH release was significant as early as one day after treatment. Released LDH levels continued to rise after days 2 and 3, suggesting further toxicity. As shown, there was no difference between baseline levels untreated and ethanol-treated cells throughout the three-day experiment. To further investigate the mechanism of cell death, apoptosis was examined using a caspase-1 assay.

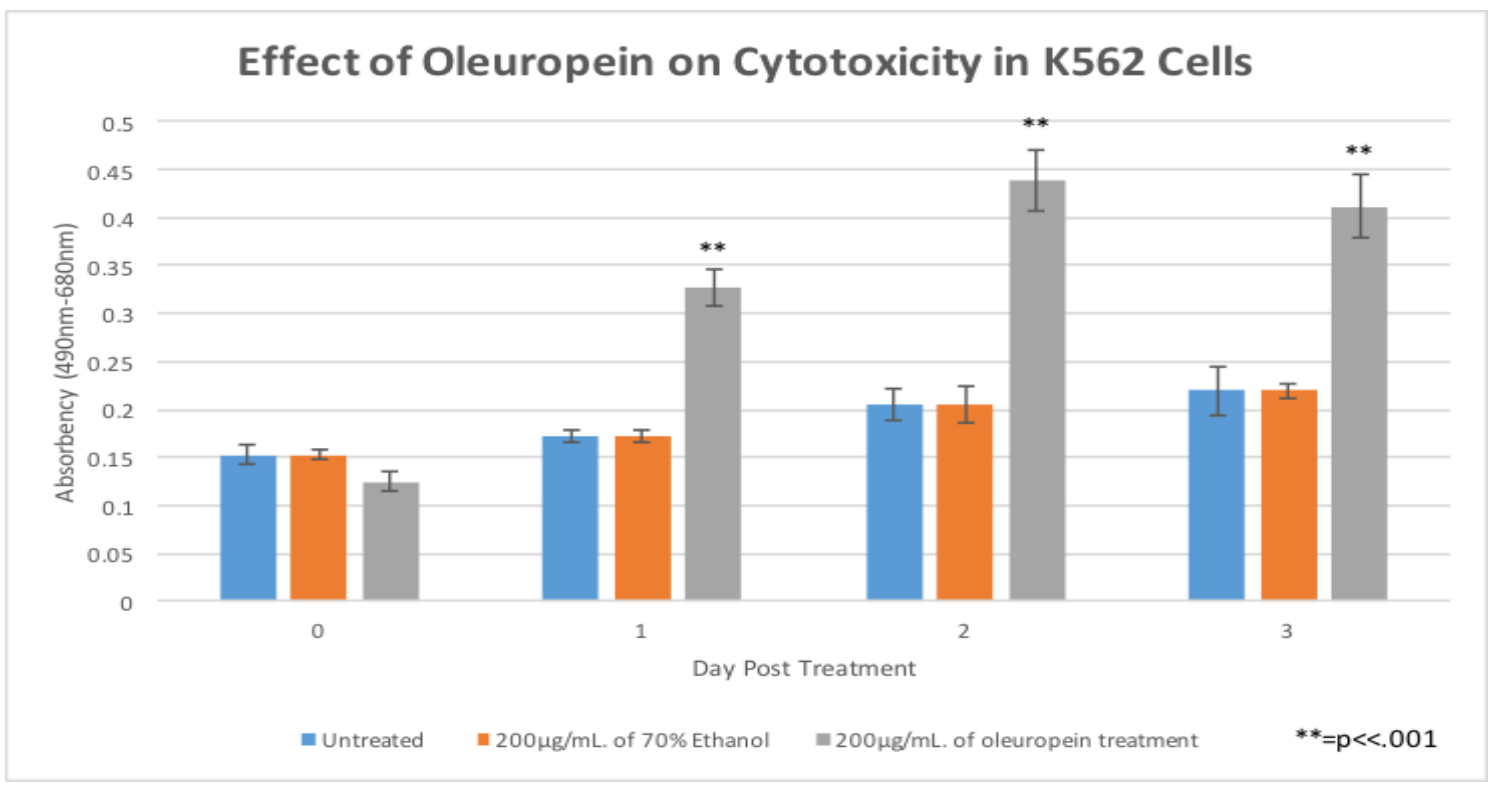

Figure 3. Effect of oleuropein on K562 cytotoxicity. K562 cells were treated with $200 \mu \mathrm{g} / \mathrm{mL}$ oleuropein (or ethanol control) for 72 hours, and cytotoxicity was measured by an LDH release assay. Average absorbance related to released LDH levels is shown (+/-stdev). A student's t-test was used for statistical analysis. 
As shown in Figure 4, only baseline levels of caspase-1 were seen after one day of oleuropein treatment, comparable to controls. However, a significant increase in caspase-1 activity was observed after 48 hours of treatment.

\section{Effect of Oleuropein on Apoptosis in K562 Cells}

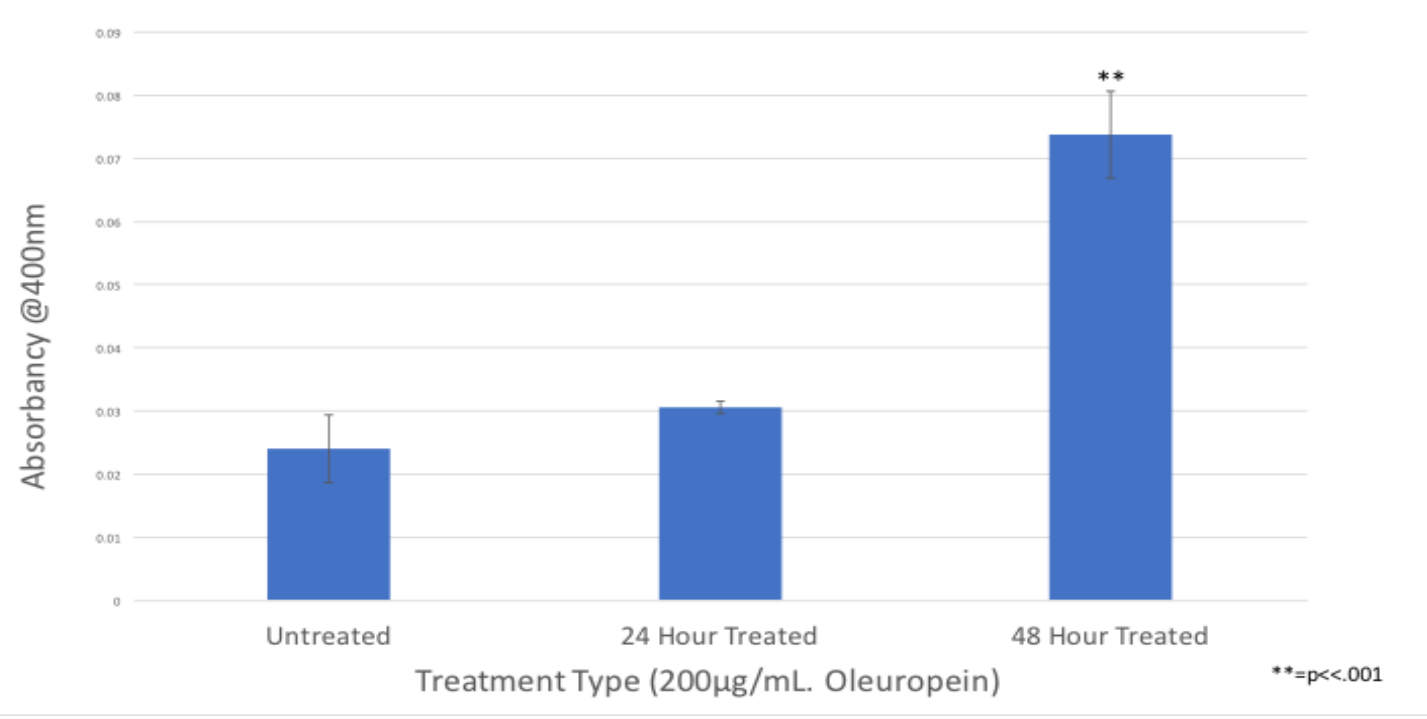

Figure 4. Effect of Oleuropein on $K 562$ apoptosis. K562 cells were treated with $200 \mu \mathrm{g} / \mathrm{mL}$ oleuropein (or ethanol control) for 72 hours, and apoptosis was measured using a Caspase-1 activity assay. Average absorbance related to caspase-1 activity is shown (+/-stdev). A student's t-test was used for statistical analysis.

Given its demonstrated effects on K562 cells, it was decided to determine if oleuropein treatment affected levels of peroxiredoxin antioxidant proteins in these cells. Western blotting was used to measure the levels of five of the six peroxiredoxin proteins after oleuropein treatment. As shown in Figure 5, there was a significant reduction of
Peroxiredoxin 1 by 8 hours after treatment, and levels remained lower after 24 hours (Fig 5A). Quantification of the Prdx1 levels showed a nearly 50\% reduction in $\operatorname{Prdx} 1$ at both time points. In contrast, expression of Prdxs 2, 3, 4, and 6 did not change when comparing untreated, 8 hour treatment, and 24 hour treatments.
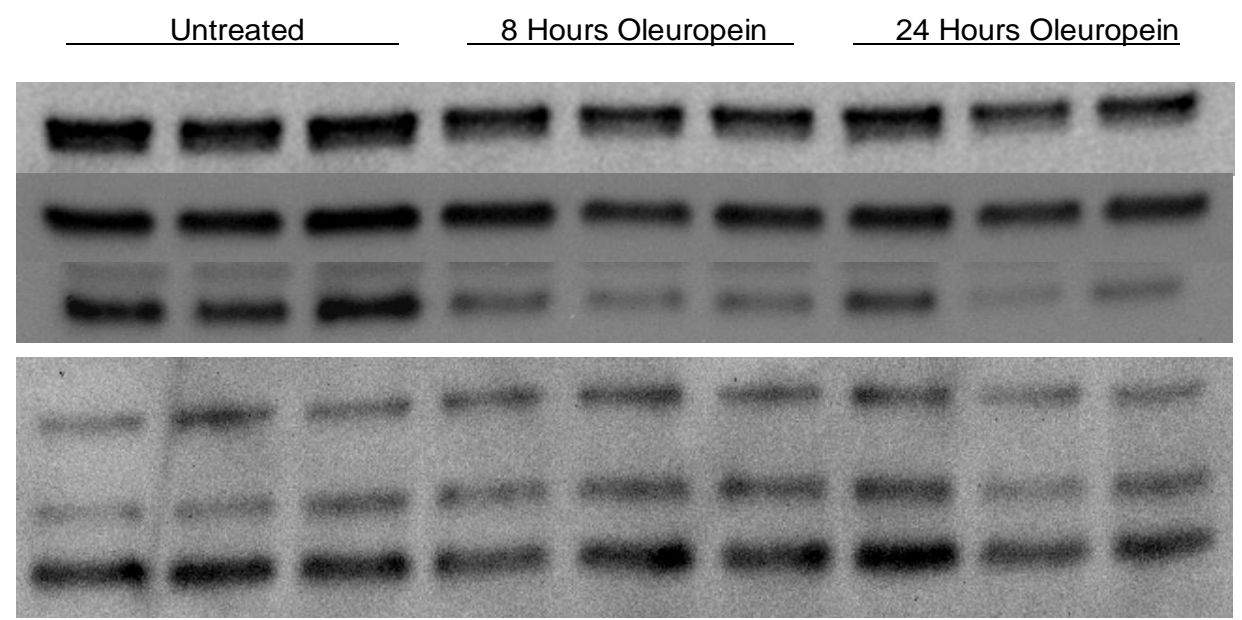

GAPDH

PRDX-6

PRDX-1

GAPDH

PRDX-4

PRDX-2

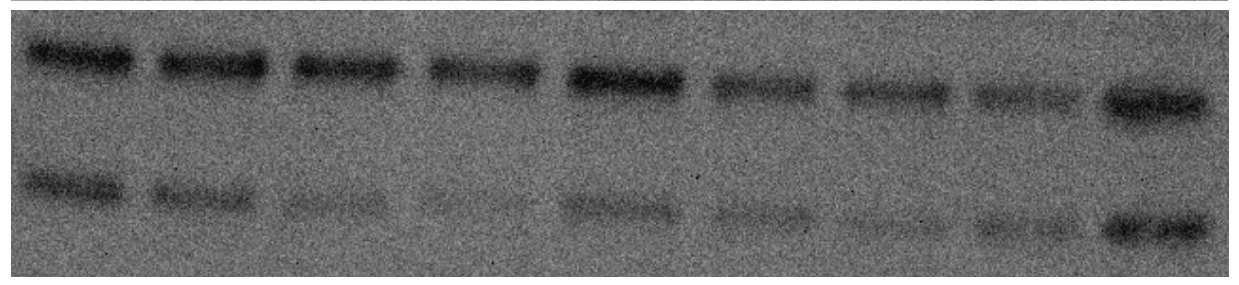

GAPDH

PRDX-3

Figure 5A 


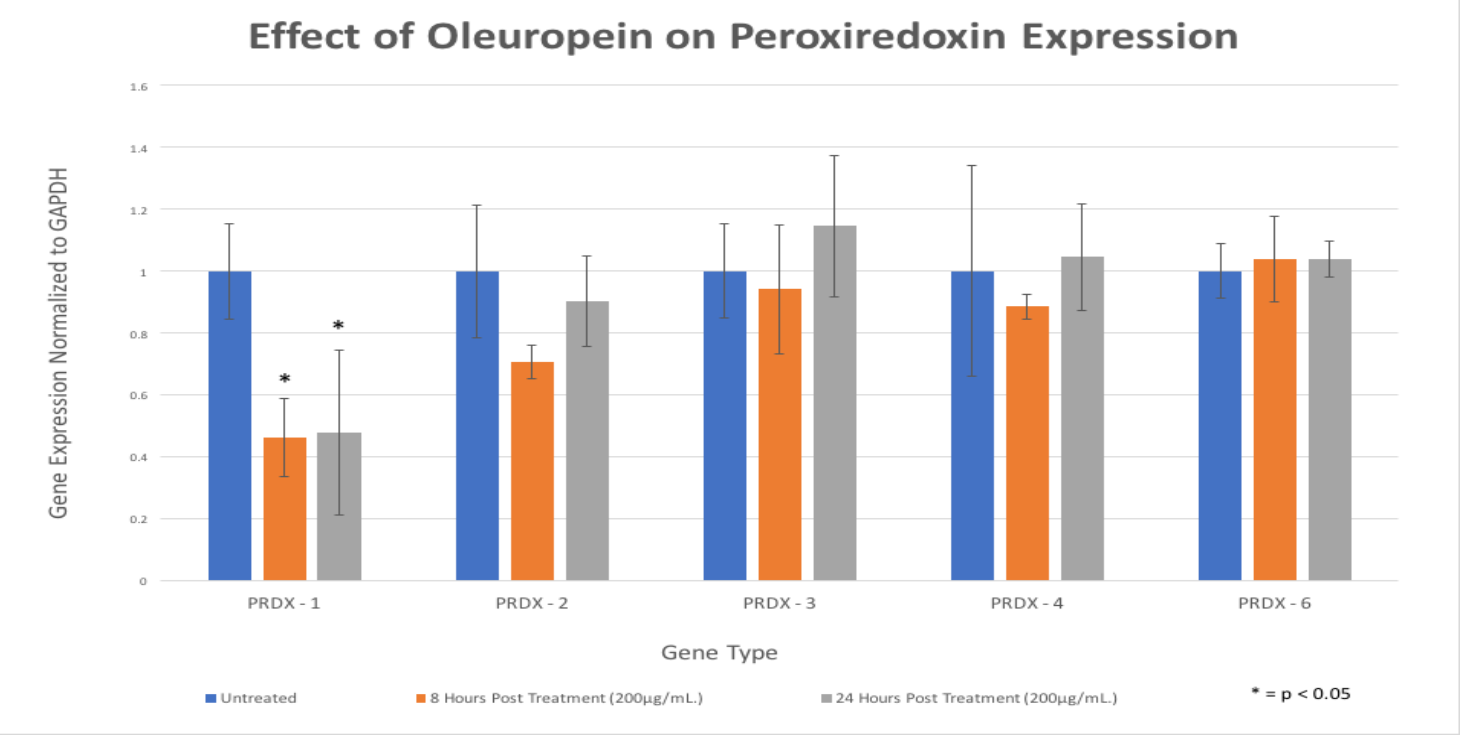

Figure 5B

Figure 5. Expression of Peroxiredoxin Proteins in Oleuropein-treated K562 Cells. Protein expression of Prdxl, 2, 3, 4 and 6 in the presence and absence of oleuropein treatment (200 $\mu \mathrm{g} / \mathrm{mL}$.) was measured by western blotting. (A) Representative western blot; (B) Quantification of relative expression levels of Peroxiredoxin proteins using GeneSys. All protein levels are normalized to levels of Gapdh.

\section{DISCUSSION}

Oleuropein is thought to be a promising anticancer agent due to its powerful antioxidant and anti-angiogenic properties. This study aimed to determine the effect of oleuropein on K562 human leukemia cells, to understand more about its mechanism of action and ability to regulate antioxidant expression. The results confirmed that oleuropein significantly decreased cell growth and viability, which correlated with an increase in cytotoxicity and apoptosis in treated cells. These data are consistent with previous reports (21).

These data suggest that oleuropein is cytotoxic to K562 cells, and that these cells are dying, at least in part, by apoptosis. While this may explain the significant reduction in cell density we observed in our studies, it is possible that oleuropein additionally has a growth-inhibitory property. There was a clear dose-response to oleuropein in these cells, suggesting that the range of concentrations used are not above a threshold for maximum toxicity. Further examination of the dose-effect of oleuropein will be important so the most physiologically relevant (yet effective) concentrations can be used in further studies.

The ability of oleuropein to down-regulate Prdx 1 is interesting. Previous studies from the Phelan lab and others have shown that many cancer cells up regulate peroxiredoxins, likely as a mechanism to withstand and combat increased oxidative stress $(12,22)$. It is possible that the reduction of Prdx1 in response to oleuropein may assist in mediating its cytotoxic effects in these cells. Prdx1 is known to be an important antioxidant in blood cells, so this is quite possible, however will require further investigation to confirm.

Continued studies are underway in our lab to examine other signaling and antioxidant pathways that are altered by this treatment, in an effort to further understand the mechanism of action in K562 cells, and the possibility of oleuropein as an anti-cancer treatment.

\section{ACKNOWLEDGEMENTS}

This work was supported by funding from Fairfield University College of Arts and Sciences, as well as research support from the Mancini Family, Guillet family, and Femia Science Fund.

\section{REFERENCES}

[1] Acquaviva, R., Di Giacomo, C., Sorrenti, V., Galvano, F., Santangelo, R., Cardile, V., Gangia, S., D'Orazio, N., Abraham, N. G., Vanella, L."Antiproliferative effect of oleuropein in prostate cell lines". International Journal of Oncology 2012. 41(1): 31-38.

[2] Andersson LC, Nilsson K, Gahmberg CG. K562-a human erythroleukemic cell line. International Journal of Cancer. 1979Feb $15 ; 23(2): 143-7$. 
[3] Boss A, Bishop K, Marlow G, Barnett M, Ferguson L. Evidence to support the anti-cancer effect of olive leaf extract and future directions. Nutrients. 2016 Aug;8(8):513.

[4] Butterfeld LH, Merino A, Golub SH and Shau $\mathrm{H}$ : From cyto- protection to tumor suppression: the multifactorial role of peroxiredoxins. Antioxid Redox Signal 1999. 1: 385-402.

[5] Cao Z, Lindsay JG. The peroxiredoxin family: an unfolding story. InMacromolecular Protein Complexes 2017 (pp. 127-147). Springer, Cham.

[6] Elamin MH, Daghestani MH, Omer SA, Elobeid MA, Virk P, Al-Olayan EM, Hassan ZK, Mohammed OB, Aboussekhra A. Olive oil oleuropein has anti-breast cancer properties with higher efficiency on ER-negative cells. Food and chemical toxicology. 2013 Mar 1;53:310-6.

[7] Karihtala, P, Mantyniemi A, Kang SW, Kinnula VL and Soini Y: Peroxiredoxins in breast carcinoma. Clin Cancer Res 2003. 15: 3418-3424.

[8] Kinnula VL, Lehtonen S, Sormunen R, Kaarteenaho-Wiik R, Kang SW, Rhee SG and Soini Y: Overexpression of peroxire- doxins I, II, III, V, and VI in malignant mesothelioma. J Pathol 2002. 196: 316-323.

[9] Kinnula VL, Paakko $\mathrm{P}$ and Soini Y: Antioxidant enzymes and redox regulating thiol proteins in malignancies of human lung. FEBS Lett 2004. 569: 1-6.

[10] Lehtonen ST, Svensk AM, Soini Y, Paakko P, Hirvikoski P, Kang SW and Saily M: Peroxiredoxins, a novel protein family in lung cancer. Int J Cancer 2004. 111: 514-521.

[11] Lennicke C, Rahn J, Lichtenfels R, Wessjohann LA, Seliger B. Hydrogen peroxide-production, fate and role in redox signaling of tumor cells. Cell Communication and Signaling. 2015 Dec;13(1):39.

[12] McDonald, C.; Muhlbauer, J.; Perlmutter, G.; Taparra, K.; Phelan, S.A. Peroxiredoxin proteins protect mcf-7 breast cancer cells from doxorubicin-induced toxicity. Int J Oncol 2014, 45, 219-226.

[13] Moran JM, Leal-Hernandez O, Canal-Macias ML, Roncero-Martin R, Guerrero-Bonmatty R, Aliaga I, Zamorano JD. Antiproliferative properties of oleuropein in human osteosarcoma cells. Natural product communications. 2016 Apr;11(4): $1934578 X 1601100418$.

[14] Nelson KJ, Knutson ST, Soito L, Klomsiri C, Poole LB, Fetrow JS. Analysis of the peroxiredoxin family: using active-site structure and sequence information for global classification and residue analysis. Proteins: Structure, Function, and Bioinformatics. 2011 Mar;79(3):947-64.

[15] Noh DY, Ahn SJ, Lee RA, Kim SW, Park IA and Chae HZ: Overexpression of peroxiredoxin in human breast cancer. Anticancer Res 2001. 21: 2085-2090.

[16] Özcan MM, Matthäus B. A review: benefit and bioactive properties of olive (Olea europaea L.) leaves. European Food Research and Technology. 2017 Jan 1;243(1):89-99.

[17] uan C, Cha EJ, Lee HL, Han KH, Lee KM and Kim WJ: Enhanced expression of peroxiredoxin I and VI correlates with development recurrence and progression of human bladder cancer. J Urolol 2006. 175: 1512-1516.

[18] Rhee SG. Overview on peroxiredoxin. Molecules and cells. 2016 Jan 31;39(1):1.

[19] Ruzzolini J, Peppicelli S, Andreucci E, Bianchini F, Scardigli A, Romani A, la Marca G, Nediani C, Calorini L. Oleuropein, the main polyphenol of Olea europaea leaf extract, has an anti-cancer effect on human braf melanoma cells and potentiates the cytotoxicity of current chemotherapies. $\quad$ Nutrients. 2018 Dec;10(12):1950.

[20] Sabry OM. Beneficial health effects of olive leaves extracts. J Natural Scien Res. 2014;4:1-9.

[21] Samet I, Han J, Jlaiel L, Sayadi S, Isoda H. Olive (Olea europaea) leaf extract induces apoptosis and monocyte/macrophage differentiation in human chronic myelogenous leukemia K562 cells: insight into the underlying mechanism. Oxidative medicine and cellular longevity. Vol 2014, Article ID 927619, 16 pages.

[22] Tehan, L.; Taparra, K.; Phelan, S. Peroxiredoxin over expression in mcf-7 breast cancer cells and regulation by cell proliferation and oxidative stress. Cancer Invest 2013, 31, 374-384.

Citation: Sophia R. Fagan, Natalie M. Fulco, Dr. Shelley A. Phelan. Oleuropein Reduces Prdxl Expression, Cell Proliferation and Viability in K562 Human Leukemia Cells. ARC Journal of Cancer Science. 2019; 5(1):17-24. DOI:dx.doi.org/10.20431/2455-6009.0501004.

Copyright: (C) 2019 Authors. This is an open-access article distributed under the terms of the Creative Commons Attribution License, which permits unrestricted use, distribution, and reproduction in any medium, provided the original author and source are credited. 